\title{
THERMAL DECOMPOSITION AND KINETIC STUDIES OF TANNIC ACID USING MODEL FREE-METHODS
}

\author{
NAUSHAD AHMAD ${ }^{\prime *}$, MANAWWER ALAM ${ }^{2}$, MU. NAUSHAD ${ }^{1}$ ANEES A. ANSARI BASEL F. ALRAYES MSHARI \\ A. ALOTAIBE 5
}

${ }^{1}$ Department of Chemistry, College of Science, Riyadh-11451, King Saud University, Kingdom of Saudi Arabia ${ }^{2}$ Research Centre, College of Science, Riyadh-11451, King Saud University, Kingdom of Saudi Arabia

${ }^{3}$ King Abdullah Institute for Nanotechnology, Riyadh-11451, King Saud University, Kingdom of Saudi Arabia

${ }^{4}$ Central Laboratory, College of Science, Riyadh-11451, King Saud University, Kingdom of Saudi Arabia

${ }^{5}$ Department of Chemistry, College of Science, Prince Sattam bin Abdulaziz, Alkharj-11942, University, Kingdom of Saudi Arabia

\section{ABSTRACT}

In this manuscript, thermal and kinetic features of a tannic acid was studied by simultaneous TG-DTA techniques in the nitrogen atmosphere at four heating rate. It was observed that thermal decomposition of its constituents occurred in two steps. Model free isoconversional methods namely modified Coast-Redfern (CR), Kissinger-Akahira-Sunose (KAS), Flynn-Wall-Ozawa (FWO) and Freidman (FR) were used for revelation of decomposition kinetics $\left(E_{\mathrm{a}}\right.$ and ln $A$ ) on the whole range of temperature. Mechanisms of decomposition process have been found to follow first order of decomposition rate. Reaction order does not have a substantial effect on the process because of the high value of pre-exponential factor. It was observed that, at the last stage of decomposition process, value of activation energy and pre-exponential factor increased. Decomposition of tannic acid was confirmed by IR spectroscopy.

Keywords: Tannic acid; Thermal decomposition; kinetics; Isoconversional methods

\section{INTRODUCTION}

The study about the decomposition and thermal stability of solid materials either inorganic or organic is of wide technological importance for investigating reaction mechanisms and kinetic triplet $(E, \ln A$ and $f(\alpha)$ or $g(\alpha))$ [1-3]. Broadly, thermal study can provide important facts on temperature dependent properties of materials, thermally induced processes; and theoretica information of reaction mechanism and kinetics of solid state decompositions [4-6]. Kinetic triplets predict how a system approaches equilibrium and also help to understand the mechanism of the decomposition steps [7]. Numerous researchers have accentuated the practical and theoretical significance on these processes [8-11]. A systematic understanding of decomposition kinetics can be useful in elucidating reaction mechanism, transformations (melting, sublimation, and polymorphic transformation), quality of products, optimization of process parameters and the course of reaction. Numerous solidstate kinetic reactions are substantially differing from homogenous reaction like solution or gases. These differences include experimental procedures like pre-treatments, sample amounts and length of induction period employed for their research and computation approaches for evaluating data [12]. Therefore, it has become essential to understand the environmental influence of material properties and its decomposition mechanism. If the rate of decomposition can be measured precisely, then it becomes possible to reveal the material properties. Solid-state kinetics and thermal behavior have been elucidate many forms but they involve mass or enthalpy changes (TGA, DTA and DSC) are of high attention of scientist since a long time [13]. The thermal decomposition data generated from thermogravimetric analytical (TGA) technique have been extensively used to determine the composition of materials, kinetic and thermodynamic parameters $\left(\mathrm{E}_{\mathrm{a}}, \mathrm{A}, \Delta \mathrm{H}, \Delta \mathrm{S}\right.$ and $\left.\Delta \mathrm{G}\right)$ and lifetime predictions, which are practical applications for large number of processes $[14,15]$. TGA can be monitoring by mass changes in different stages that occurs at given temperature or temperature range of controlled heating rate [16]. The decomposition process by TG technique can be influenced by experimental conditions $[17,18]$ like temperature, gas flow rate, heating rate (isothermal and non-isothermal), the nature of gas flowing, sample mass or material properties (composition, shape and size of particles), moisture content as well as the mathematical methods used to calculate data. Solid-state thermal kinetics can be mechanistically classified as diffusion, geometrical contraction, nucleation and applied reaction order models. Many studies of TG data have been used for determination of kinetic parameters, such as isothermal and non-isotherma methods. Numerous mathematical approaches have been established to deduce experimental data for heating procedures, isothermal and non-isothermal. These methods generally fall into two categories: model-fitting and model-free. In this article, we have reported the decomposition and kinetic parameters of tannic acid examined by thermogravimetric-derivative (TG-DTA) technique in the presence of nitrogen gas at heating rate of $5,10,20$ and $25^{\circ} \mathrm{C} \min ^{-1}$ using non-isothermal isoconversional (FWO, KAS, modified CR and FR) methods Briefly, tannic acid is a polymer of gallic acid and glucose (Figure 1) and found in woods like oak, walnut, seeds, bark, cones and heartwood. It has antibacterial, anti-enzymatic, anti-oxidant, anti-mutagenic and astringent properties and provides natural defense for woods against wildfire, decomposition and infestation by insects and an important ingredient in food, medicines and wine.<smiles>O=C(OC[C@H]1O[C@@H](OC(=O)c2cc(O)c(O)c(OC(=O)c3cc(O)c(O)c(O)c3)c2)[C@H](OC(=O)c2cc(O)c(O)c(OC(=O)c3cc(O)c(O)c(O)c3)c2)[C@H](OC(=O)c2cc(O)c(O)c(OC(=O)c3cc(O)c(O)c(O)c3)c2)[C@@H]1OC(=O)c1cc(O)c(O)c(OC(=O)c2cc(O)c(O)c(O)c2)c1)c1cc(O)c(O)c(O)c1</smiles>

Fig. 1. Structure of tannic acid

\section{EXPERIMENTAL}

Tannic acid $\left(\mathrm{C}_{76} \mathrm{H}_{52} \mathrm{O}_{46}\right.$, MW $\left.1701.20 \mathrm{~g} \mathrm{~mol}^{-1}\right)$ was obtained from BDH Poole England. TG-DTA of tannic acid was performed using Mettler Toledo AG, Analytical CH-8603 (Schwerzenbach, Switzerland). For each experiment, approximately $0.5 \mathrm{mg}$ of tannic acid was loaded into alumina crucibles in the heating zone of TGA. For non-isothermal, simultaneous TG-DTA sample were scanned from 50 to $800^{\circ} \mathrm{C}$ at heating rate of $5,10,20$ and $25^{\circ} \mathrm{C} \mathrm{min}^{-1}$ with the flow rate of $20 \mathrm{~mL} \mathrm{~min}^{-1}$ of nitrogen gas. The Fourier transform infrared (FTIR) spectra before and after thermal analysis were recorded in the range of $4000-400 \mathrm{~cm}^{-1}$ on a Bruker Tensor 27 FT-IR spectrophotometer. 
Methods of Kinetic parameter estimation

TG-DTA method is very important for the determination of decomposition temperature/steps and kinetics parameters for solid materials. The present work reports the estimation of kinetic parameters by model free isoconversional methods. The basic proclamation of these methods is that the rate of reaction for a constant degree of conversion depends only on temperature and a series of experiments has to be measured at multiple heating rates. The knowledge of $E$ and $\ln A$ versus $\alpha$ allows detecting multi step processes and reaction mechanism over a wide temperature range.

The kinetic equation of thermal decomposition process can be written as:

$$
(d \alpha / d t)=k(T) f(\alpha)=A \exp \left(-E_{a} /_{R T}\right) f(\alpha)
$$

where $\alpha$ is a fraction decomposed at time $t, k(T)$ is temperature dependent function, $f(\alpha)$ is conversion function $(\alpha)$ which depends on the mechanism of decomposition, $A$ is frequency factor, $T$ is absolute temperature, $\mathrm{R}$ gas constant $\left(8.314 \mathrm{~J} \mathrm{~mol}^{-1} \mathrm{~K}^{-1}\right)$ and $E_{a}$ is activation energy.

Introducing the linear heating rate $(\beta)$ in non-isothermal conditions Eq. (1) can be expressed as:

$$
(d \alpha / d T)=(A / \beta) f(\alpha) \exp \left(\left(-E_{a}\right) / R T\right)
$$

Thus, activation energy of a thermal process under linear heating rate would be estimated from the plot of the left hand side verses $\mathrm{T}^{-1}$ of Eq. (2). On integration and approximation, Eq. (2) leads to

$$
\left.g(\alpha)=\int_{0}^{\alpha} d(\alpha) / f(\alpha)\right)=(A / \beta) \int_{T_{0}}^{T} \exp \left(-E_{a} / R T\right) d T
$$

$g(\alpha)$ is integral form of the $f(\alpha)$, which is the reaction model that depends on reaction mechanism. This equation permit direct evolution of experimental data by mass-loss recorded in a thermogravimetric analysis under a linear heating rate.

In the present study, the non-isothermal kinetics for thermal decomposition were evaluated according to Kissinger-Akahira-Sunose (KAS), Flynn-WallOzawa (FWO), modified Coasts-Redfern (CR) and Friedman (FR) methods.

Flynn-Wall-Ozawa (FWO) is an isoconversional method that can determine activation energy without knowledge of reaction order [19, 20]. Integration and taking natural logarithms of eq (2) by using Doyle approximation [21] is written as:

$$
\left.\ln \beta=-1.052\left(E_{a} / R T\right)+\ln \left(A E_{a}\right) / R\right)-\ln g(\alpha)-5.3305
$$

where $E_{\mathrm{a}}, A, \beta$ and $T$ have the known denotations. The $E_{\mathrm{a}}$ at various degree conversions can be obtained from $\ln \beta$ versus $1 / T$ plot. In this method, conversion dependence function $(f(\alpha)$ or $g(\alpha)$ ) are not required.

The modified CR method [22] is a multi-heating rate model-free isoconversional approach. It is based on the equation:

$$
\left.g(\alpha)=\int_{0}^{\alpha} d(\alpha) / f(\alpha)\right)=(A / \beta) \int_{T_{0}}^{T} \exp \left(-E_{a} / R T\right) d T
$$

where $T_{\mathrm{o}}$ is temperature at onset of reaction. This equation on integration for the first order of reaction $(\mathrm{n}=1)$ gives,

$$
\ln \left(-\frac{\ln (1-\alpha)}{\mathrm{T}^{2}}\right)=-\mathrm{E}_{\mathrm{a}} / \mathrm{RT}+\ln \mathrm{AR} / \beta \mathrm{E}_{a}
$$

To use this equation at a selected common value of conversion degree for different heating rates, the left-hand side should be plotted against $1 / T$ and giving a straight lines of slope $-E / R$ while $A$ from intercept value. If the values of $E_{\mathrm{a}}$ vary with the variation of $\alpha$, the data should be interpreted in terms of multi-step process [23].

Kissinger-Akahira-Sunose (KAS) method is based on the Coats-Redfern approximation and similar to the FWO method [24, 25], which is described by the following equation:

$$
\ln \left(\beta / T^{2}\right)=\ln \left[A R / E_{a} g(\alpha)\right]-E_{a} / R T
$$

For constant $\alpha$, a plot of $\ln \beta / T^{2}$ versus $1 / T$ is a straight line whose slope is $E / R T$.

Friedman method [26] is an isoconversional differential method, relates the logarithm of rate of reaction with the inverse temperature for a constant $\alpha$, based on the following equation:

$$
\ln \left(\beta \frac{d_{\alpha}}{d T}\right)=-\frac{E_{a}}{R T}+\ln \mathrm{A}+\ln f(\alpha)
$$

The plot of left hand side versus $1 / T$ allows estimation of the activation energy.

\section{RESULTS AND DISCUSSION}

Nonisothermal decomposition of Tannic acid (TG-DTA)

TG and its corresponding DTA curves of tannic acid are shown in Figure 2 and decomposition data are summarized in Table1. The TG curves are characterized by two mass losses during decomposition. The DTA curves also shows splitting, confirming the two step process. The values of initial temperature $\left(\mathrm{T}_{\mathrm{o}}\right)$, temperature of completion $\left(\mathrm{T}_{\text {end }}\right)$, and maximum temperature ( $\mathrm{T}_{\text {m }}$ ) acquired from TG and DTA for the thermal decomposition of tannic acid show that these values increases as the heating rate increased. The shift of TG curves with increasing heating rate to higher temperature could be ascribed due to short time period required for a tannic acid to reach a given temperature and particle size distribution [27]. Figure 1a clearly showed that residual mass increased with level of heating rates and suggested different kind of final products. The first minor peak occurs in the temperature range 50-95 ${ }^{\circ} \mathrm{C}$ accompanied by removal of small molecules like $\mathrm{H}_{2} \mathrm{O}, \mathrm{CO}, \mathrm{CO}_{2}$, and phenol from high molecular weight macromolecules into smaller chain fragments. The next major decomposition peak occurs in the temperature range 190-460 ${ }^{\circ} \mathrm{C}$ and corresponds to the depolymerisation/hydrolysis of tannic acid. After decomposition of tannic acid all groups were absent which shows that tannic acid completely decomposed and the residues have only carbon, confirmed by FTIR (Fig. 3).

Table1. Data from TG and DTA curves for decomposition process of tannic acid at different heating rates in nitrogen atmosphere.

\begin{tabular}{|c|c|c|c|c|c|c|}
\hline \multirow{2}{*}{$\begin{array}{c}\text { Heating } \\
\text { rate ( } \beta)\end{array}$} & \multicolumn{3}{|c|}{ Step 1 } & \multicolumn{3}{c|}{ Step 2 } \\
\cline { 2 - 7 } & $\mathrm{T}_{\text {on }} /{ }^{\circ} \mathrm{C}$ & $\mathrm{T}_{\text {end }} /{ }^{\circ} \mathrm{C}$ & $\mathrm{T}_{\max 1} /{ }^{\circ} \mathrm{C}$ & $\mathrm{T}_{\text {on }} /{ }^{\circ} \mathrm{C}$ & $\mathrm{T}_{\text {end }} /{ }^{\circ} \mathrm{C}$ & $\mathrm{T}_{\max 2} /{ }^{\circ} \mathrm{C}$ \\
\hline 5 & 50.10 & 106.05 & 67.15 & 194.13 & 437.11 & 308.16 \\
\hline 10 & 51.94 & 122.13 & 73.25 & 196.09 & 439.61 & 319.22 \\
\hline 20 & 52.54 & 145.09 & 93.03 & 215.34 & 455.16 & 327.62 \\
\hline 25 & 54.85 & 151.22 & 94.16 & 223.08 & 460.17 & 333.19 \\
\hline
\end{tabular}

Nonisothermal decomposition kinetics

Fig. 4 represents modified CR, KAS, FWO and FR plots of $\ln (-\mathrm{b} \ln (1-\alpha) /$ $\left.\mathrm{T}^{2}\right), \ln \left(\beta / \mathrm{T}^{2}\right), \ln \beta$ and $\ln \left(\beta \mathrm{d}_{\alpha} / \mathrm{dt}\right)$ against inverse of decomposition temperature $(1000 / T)$ for tannic acid at four different heating rates on selected conversion points $(\alpha=0.05-0.85)$ in nitrogen atmosphere, respectively. The activation energy and frequency factor values for selected conversion point are calculated by the slope and intercept of trend-line after substituting appropriate quantities. It was observed that in all the cases, good straight lines were obtained. In most cases, the value of correlation coefficient was found higher than 0.985 . The estimated values of activation energy and frequency factor are given in Table 2 and plotted in Fig. 5. From Fig. 5a, it is quite clear that same shape of curves were found by applied methods and activation energy passes through a minimum value at $5 \%$ and maximum at $55 \%$ conversion. As it can be seen, dependence is quite complex, practically observed that activation energy changes with degree of conversion. It can be found that kinetic parameters $\left(\mathrm{E}_{\mathrm{a}}\right.$ and $\ln$ A) initially increased, then tends to maintain it constant $(\alpha=20 \sim 50 \%)$ and finally rises again above $75 \%$, indicated that degradation mechanism varies with mass changes which are controlled by diffusion process than by kinetic factor [28]. The conversion values upto $20-60 \%$ is characterized by dehydration, decarboxylation and pyrolysis reactions with low activation energies. These decomposition mechanisms are resulted mainly from the break of weak chemical bond bonds, such as, $\mathrm{C}-\mathrm{O}, \mathrm{O}-\mathrm{H}$ bonds in molecular structure (Fig. 2). These weak bonds have low rupture energy which commensurate with pyrolysis gaseous products such as $\mathrm{H}_{2} \mathrm{O}, \mathrm{CO}_{2}, \mathrm{H}_{2}$ and light hydrocarbons. At higher conversions than $70 \%$, new bond destructions might occur. Table 2 
shows the activation energy obtained by CR, KAS and FWO methods agree very well after fitting the data. However the activation energy obtained from the FR method are higher than the values obtained from the other three methods, due to different approximations of the temperature integral by applied methods [29]. The average values of $\mathrm{E}_{\mathrm{a}}$ for FWO, KAS and CR methods obtained in the range are also lower than average values of $\mathrm{E}_{\mathrm{a}}$ obtained for FR method.
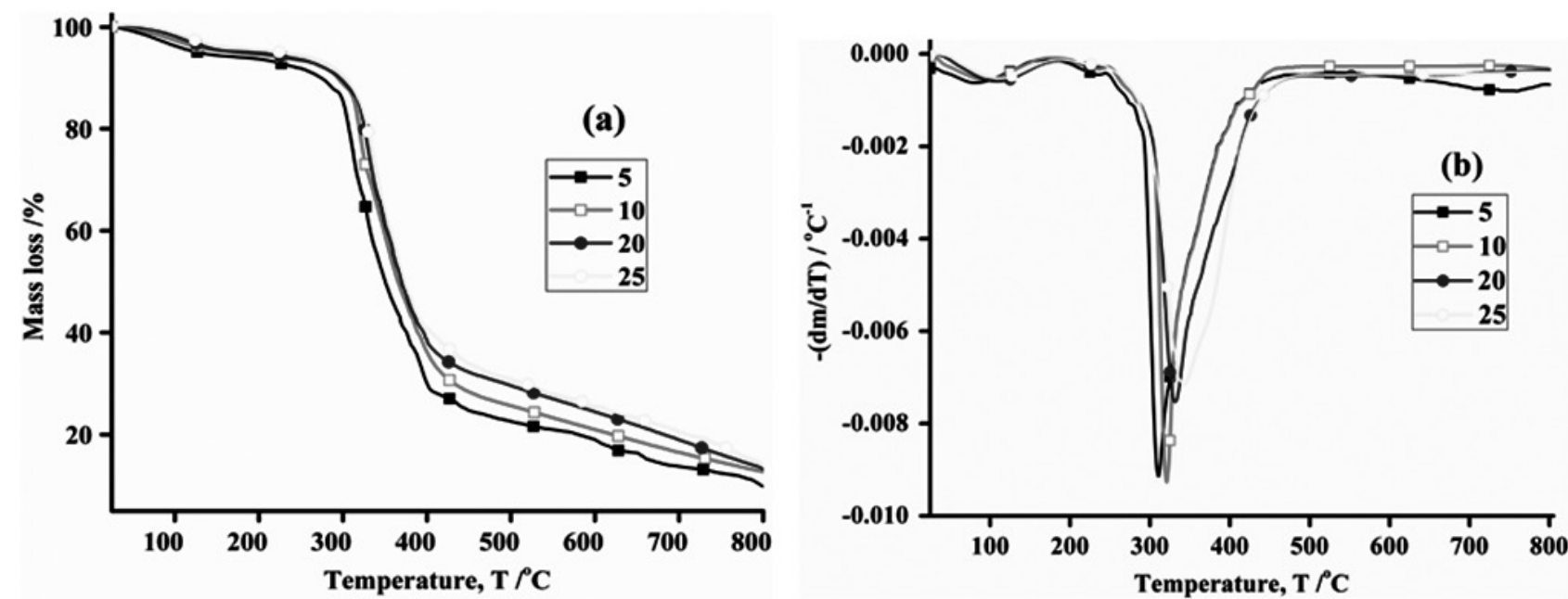

Fig. 2. TG (a) and DTA (b) thermal decomposition curves of tannic acid in nitrogen atmosphere at different heating rates.

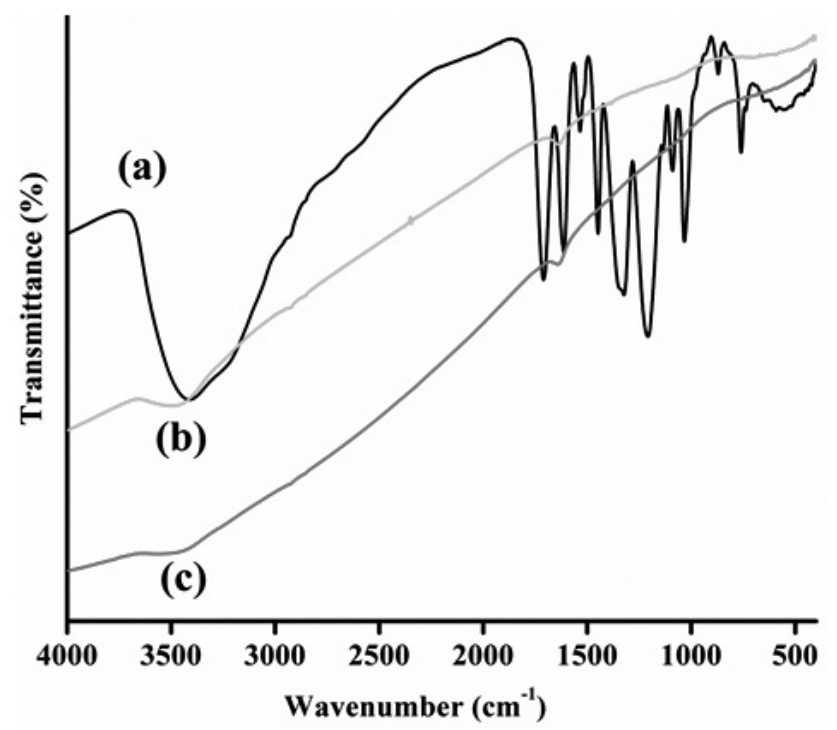

Fig. 3. FT-IR spectra of (a) Before decomposition (b) After decomposition at $5^{\circ} \mathrm{C} \mathrm{min}-1$ and (c) $25^{\circ} \mathrm{C} \mathrm{min}^{-1}$ of tannic acid.

\section{CONCLUSION}

Thermal degradation of tannic acid in nitrogen atmosphere under nonisothermal condition showed two mass-loss stages, one minor and other major. Four isoconversional methods namely CR, KAS, FWO and FR were tested and checked their suitability to tannic acid pyrolysis kinetics after brief mathematical manipulations to extract the final form of equation employed to estimate the activation energy and pre-exponential factor. In conclusion, a good agreement of activation energy was observed by CR, KAS and FWO methods. Friedman method leads to slightly higher values of activation energy compared with other methods. 
Table 2.Thermal kinetic parameters of tannic acid at different conversion degrees determined by CR, KAS, FWO and FR methods.

\begin{tabular}{|c|c|c|c|c|c|c|c|c|}
\hline $\begin{array}{c}\text { Conversion } \\
(\%)\end{array}$ & $\begin{array}{c}\mathrm{CR} \\
E_{a} / \mathrm{kJ} \mathrm{mol}^{-1}\end{array}$ & $\begin{array}{c}\mathrm{CR} \\
\ln A / \mathrm{min}^{-1}\end{array}$ & $\begin{array}{c}\mathrm{KAS} \\
E_{a} / \mathrm{kJ} \mathrm{mol}^{-1}\end{array}$ & $\begin{array}{c}\text { KAS } \\
\ln A / \mathrm{min}^{-1}\end{array}$ & $\begin{array}{c}\mathrm{FWO} \\
E_{a} / \mathrm{kJ} \mathrm{mol}^{-1}\end{array}$ & $\begin{array}{c}\mathrm{FWO} \\
\ln A / \mathrm{min}^{-1}\end{array}$ & $\begin{array}{c}\mathrm{FR} \\
E_{a} / \mathrm{kJ} \mathrm{mol}^{-1}\end{array}$ & $\begin{array}{c}\mathrm{FR} \\
\ln A / \mathrm{min}^{-1}\end{array}$ \\
\hline 5 & 15.21 & 1.45 & 15.21 & 1.98 & 21.26 & 0.76 & 22.79 & 0.992 \\
\hline 10 & 139.46 & 27.06 & 139.46 & 29.31 & 141.41 & 24.50 & 144.11 & 24.61 \\
\hline 15 & 205.27 & 40.84 & 205.27 & 42.65 & 208.18 & 37.14 & 213.11 & 38.00 \\
\hline 20 & 202.12 & 39.52 & 202.12 & 41.02 & 204.41 & 35.58 & 208.03 & 36.69 \\
\hline 25 & 203.25 & 39.42 & 203.25 & 40.66 & 203.64 & 35.23 & 208.21 & 36.56 \\
\hline 30 & 203.34 & 39.20 & 203.34 & 40.23 & 203.81 & 34.83 & 208.35 & 36.32 \\
\hline 35 & 210.28 & 40.44 & 210.28 & 41.28 & 211.47 & 35.82 & 216.34 & 37.50 \\
\hline 40 & 200.75 & 38.01 & 200.75 & 38.68 & 201.57 & 33.34 & 205.88 & 35.09 \\
\hline 45 & 211.08 & 39.65 & 211.08 & 40.17 & 212.52 & 34.76 & 216.27 & 36.66 \\
\hline 50 & 218.75 & 40.68 & 218.75 & 41.04 & 219.95 & 35.60 & 224.02 & 37.62 \\
\hline 55 & 239.99 & 44.07 & 239.99 & 44.30 & 240.14 & 38.71 & 245.16 & 40.90 \\
\hline 60 & 201.99 & 36.08 & 201.99 & 36.17 & 202.49 & 30.98 & 207.51 & 33.06 \\
\hline 65 & 119.42 & 19.02 & 119.42 & 20.98 & 124.38 & 15.86 & 125.13 & 17.51 \\
\hline 70 & 48.52 & 6.18 & 48.52 & 6.20 & 54.64 & 3.67 & 57.58 & 4.56 \\
\hline 75 & 37.29 & 3.41 & 37.29 & 3.588 & 43 & 1.387 & 48.91 & 2.07 \\
\hline 80 & 70.88 & 7.68 & 70.88 & 7.814 & 78.86 & 4.614 & 81.49 & 5.76 \\
\hline 85 & 91.01 & 8.85 & 91.01 & 9.518 & 99.23 & 5.908 & 102.28 & 7.25 \\
\hline Average & 153.21 & 27.74 & 154.42 & 28.56 & 157.11 & 24.04 & 160.89 & 25.36 \\
\hline
\end{tabular}
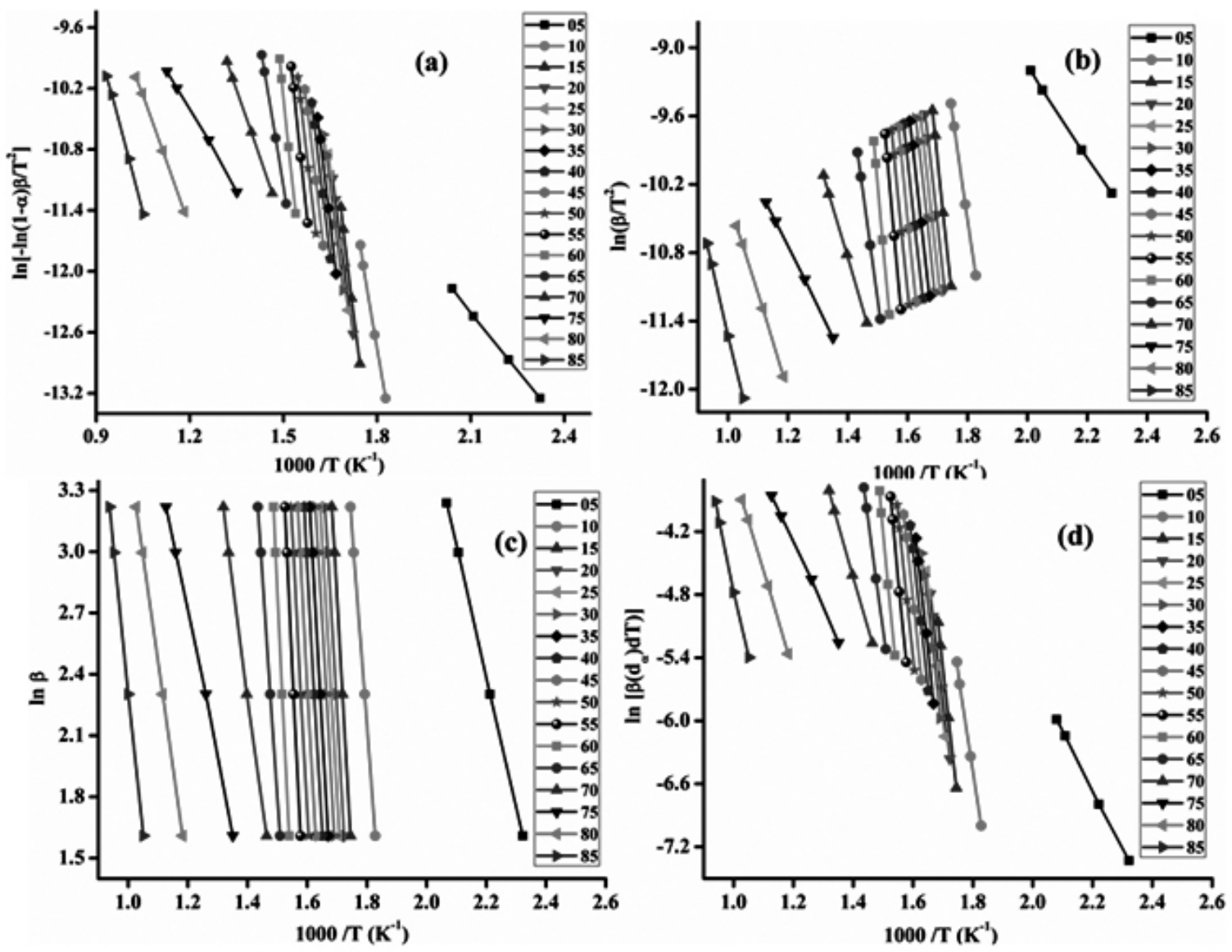

Fig. 4. (a) Coats-Redfern (CR), (b) Kissinger-Akahira-Sunose (KAS), (c) Flynn-Wall-Ozawa (FWO), and (d) Friedman (FR) linear plots of tannic acid in nitrogen atmosphere. 

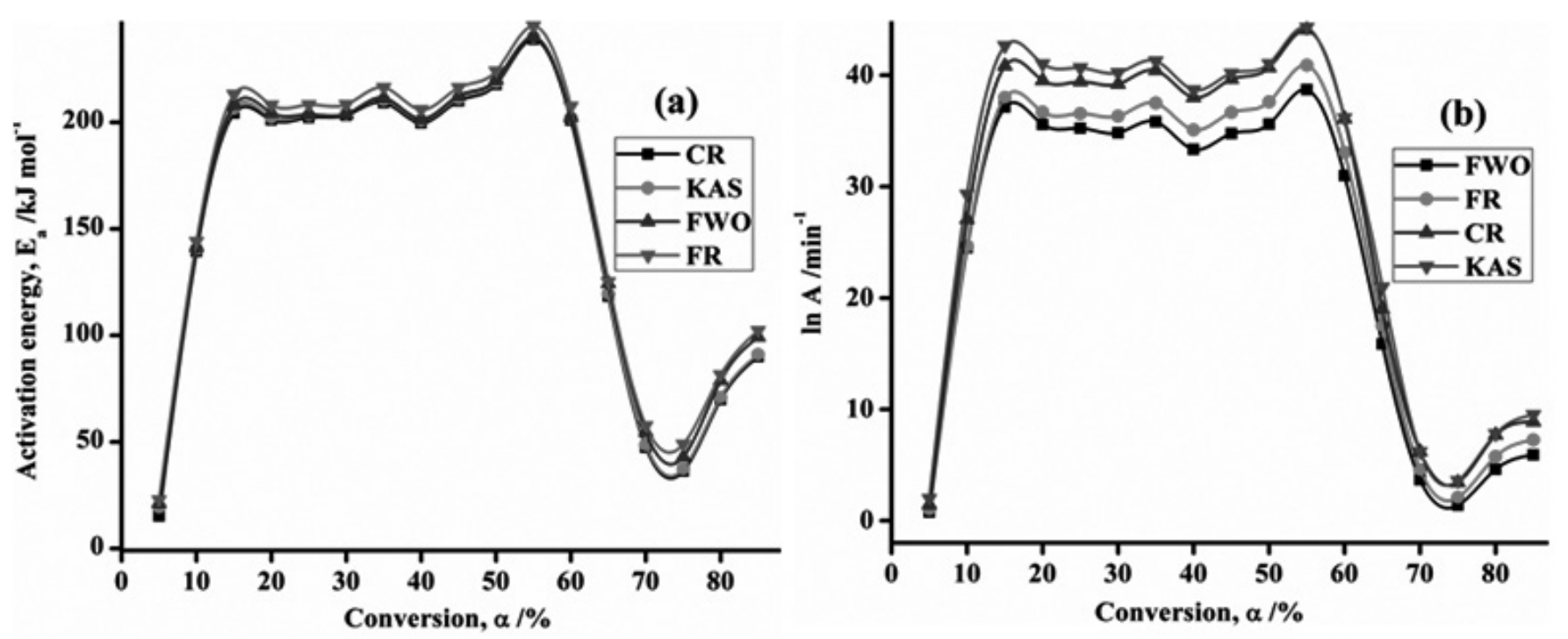

Fig. 5. Variation in (a) activation energy $\left(E_{a}\right)$ and (b) frequency factor $(\ln A)$ on selected degree of conversion $(\alpha)$ of tannic acid according to Coats-Redfern (CR), Kissinger-Akahira-Sunose (KAS), Flynn-Wall-Ozawa (FWO) and Friedman (FR) isoconversional methods.

\section{ACKNOWLEDGEMENTS}

This project was supported by King Saud University, Deanship of Scientific Research, College of Science Research Center.

\section{REFERENCES}

1. A. K. Galwey, M.E. Brown, Thermal decomposition of ionic solids, first ed. Elsevier Science BV Amsterdam, The Netherland,1999.

2. S. Vyazovkin, Anal. Chem., 2004, 76, 3299

3. J. W. Huang, C. C. Chang, C. C. Kang, M. Y. Yeh, Thermochim Acta, $2008,468,66$.

4. S. Vyazovkin, C.A. Wight, Annu. Rev. Phys. Chem., 1997,48,125.

5. J.M. Kotler, N.W. Hinman, C.D. Richardson, J.R. Scott, J. Therm. Anal Calorim., 2010, 102,23

6. C.D. Bertol, A.P. Cruz, H.K. Stulzer, F.S. Murakami, M.A.S. Silva, J. Therm. Anal. Calorim., 2010,102,187.

7. J. Malek, T. Mitsuhashi J.M. Criado, J. Mate. Res,2001,16,1862.

8. S. Vyazovkin, C.A. Wight, J. Phys. Chem., 1997,101A,8279.

9. T.B. Brill, K.J. James, Chem. Rev., 1993, 93,2667.

10. S.Vyazovkin, C.A. Wight, Int. Rev. Phys. Chem.,1998,17,407.

11. D. Dollimore, Chemical Rev., 1996, 68,63.

12. S. Vyazovkin, Inter. Rev. Phy. Chem., 2000,19,45.

13. M.E. Brown, Introduction to thermal analysis: techniques and applications, Chapman and Hall, London, 1998, pp127-151.

14. S. Vyazovkin C.A. Wight, Thermochim. Acta, 1999,340/341,53.

15. F. Rodante, S.Vecchio, M. Tomassetti, J. Pharm. Biomed Anal.,2002, 29,1031 .

16. N. Sbirrazzuoli, L. Vincent, A. Mija, N.Guigo, Chemometrics and Intelligent Laboratory Systems, 2009, 96, 219.

17. S. Vyazovkin, New J. Chem., 2000, 24,913.

18. S. Vyazovkin, Inter. J. Chem. Kinet., 1996, 28,95.

19. J.H. Flynn, L. A.Wall, J. Res. Nat. Bur. Stand.: A Phys Chem, 1966,70A, 487.

20. T. Ozawa, Bull. Chem. Soc. Jap., 1965,38,1881.

21. C. D. Doyle, Nature, $1965,207,290$.

22. A. K. Burnham, L. N. Dinh, J. Therm. Anal. Calorim., 2007,89/2,479.

23. J. T. Sun, Y. D. Huang, G. F. Gong, H. L. Cao, Polym. Degrad. Stabil., 2006,91,339.

24. H.E. Kissinger, Anal. Chem., 1957,29,1702.

25. T. Akahira, T. Sunose, "Trans. Joint Convention of Four Electrical Institutes," Paper No. 246, 1969, Research Report, Chiba Institute of Technology, Science Technology, 1971,16, pp.22-31.

26. H.L. Friedman, J. Poly.Sci., 1964,C6,183-195.
27. A. Khawam, D.R. Flanagan, Thermochim. Acta, 2005,436,101

28. R.B. Prime, "Thermosets In:Thermal Characterization of Polymeric Materials," Turi E.A.( Second Ed.), New York, Academic,1997.

29. S. Vyazovkin, J. Comput. Chem, 2001,22,178. 